\title{
Implantação do Modelo Enfermeiro Referência "Primary Nursing" em um Hospital Público Oncológico no Estado de São Paulo
}

\author{
Andrade, Daniela; Alves, Marryete Benzo; Gobo, Debora Costa; Silva, Elaine \\ Aparecida da; Baia, Wania Regina Mollo \\ Instituto do Cancer do Estado de São Paulo — daniela.andrade@icesp.org.br
}

Introdução: o Primary Nursing é um método para organização do trabalho da equipe de enfermagem, onde uma enfermeira (principal) assume a responsabilidade pela coordenação dos cuidados de enfermagem a um ou mais pacientes e sua família, tornando-se referência dentro da instituição. Designações e/ou papeis das enfermeiras: "Primary Nurse" (enfermeiro principal), a Enfermeira Associada, a enfermeira chefe e a enfermeira especialista. o método tem como principal vantagem o resgate da relação da enfermeira com o paciente, favorecendo sua autonomia e contribuindo para o estabelecimento de laços estreitos entre o cliente, família e profissional, por intermédio de um atendimento personalizado e humanizado. Objetivo: Implantação do modelo de organização do serviço de enfermagem "Primary Nursing" em um hospital público oncológico no estado de São Paulo, nas Unidades Oncocirúrgicas. Método: Estudo descritivo da implantação do método Primary Nursing. o modelo foi implantado neste hospital desde junho de 2009, e expandido para as Unidades Cirúrgicas em abril de 2010. a implantação foi realizada em etapas, desde o treinamento realizado pelas equipes médicas, a divisão das especialidades por grupos, divisão dos enfermeiros em Referência e Associado de acordo com a afinidade pelo grupo de especialidades, apresentação interna de trabalhos pelos enfermeiros, e então inicio da aplicação do modelo nas unidades. a introdução do método assistencial trouxe mudanças desde a forma convencional da divisão de pacientes na escala diária, onde os pacientes passaram a ser divididos por grupos de especialidades, tendo um enfermeiro responsável pelo gerenciamento do cuidado (referência), fazendo com que a equipe de enfermagem e a multiprofissional tivessem uma nova visão da unidade, que centraliza o planejamento dos cuidados no enfermeiro, fortalecendo a capacidade de liderança baseada em conhecimento cientifico. Resultado: Devido ao modelo assistencial ser focado na humanização, evidenciamos na prática o vinculo estreitado entre paciente e enfermeiro e o aumento de confiança em toda a equipe de enfermagem. Conclusão:. o paciente passou a levar ao enfermeiro referência suas preocupações, dúvidas e elogios, reconhecendo o cuidado individualizado que está sendo prestado. Todo o corpo de enfermagem precisa estar envolvido para que a implantação do modelo Primary Nursing ocorra na instituição, desde a elaboração do projeto de implantação, treinamento da equipe, estímulo à busca pelo conhecimento técnico-cientifico, até o plano de divulgação para os pacientes/familiares. o modelo terá impacto muito grande sobre toda a instituição que optar pelo mesmo, tornando tanto a instituição como os profissionais que atuam nela, mais humanos e dispostos a valorizar a individualidade de cada paciente e família que estarão aos seus cuidados durante um período repleto de novas experiências e ansiedades, que é a hospitalização.

Andrade, Daniela; Alves, Marryete Benzo; Gobo, Debora Costa; Silva, Elaine Aparecida da; Baia, Wania Regina Mollo. Implantação do Modelo Enfermeiro Referência "Primary Nursing" em um Hospital Público Oncológico no Estado de São Paulo. In: Anais do Congresso Internacional de Humanidades \& Humanização em Saúde [= Blucher Medical Proceedings, num.2, vol.1]. São Paulo: Editora Blucher, 2014. ISSN 2357-7282

DOI 10.5151/medpro-cihhs-10314 